\title{
Understanding and approaching the cultural gap between First World leaders and their Third World workforce: An African focus
}

\author{
E. S. van Zyl ${ }^{1 \star}$, R. Kleynhans ${ }^{1}$ and M. du Plessis ${ }^{2}$ \\ ${ }^{1}$ Department of Industrial Psychology, Faculty of Economic and Management Sciences, P .O. Box 33 (23), University of \\ the Free State, Bloemfontein 9300. South Africa. \\ ${ }^{2}$ PE Corporate Services, P. O. Box 77, Totiusdal, Pretoria 2000. South Africa.
}

Accepted 30 March, 2011

\begin{abstract}
The world is characterised by political, social and economic environmental changes. Internationalisation and globalisation for instance, have brought about world competition and require managers to interact with and manage people who are culturally diverse. The aim of this qualitative research article therefore, is to discuss an appropriate and relevant way in which First World leaders can understand and approach their Third World workforce in Africa. Important concepts are defined, with the focus on cultural intelligence and the significance thereof to the First World leaders' understanding and approach towards Third World subordinates. Cultural intelligence can be improved by inter alia, obtaining knowledge of current leadership and management practices in Africa. Therefore, leadership and management in Africa are discussed, followed by a description of a cultural intelligence implementation model of leadership. Lastly, the focus is on servant leadership as a tool to implement cultural intelligence in the organisational context.
\end{abstract}

Key words: First world leader, third world workforce, culture, cultural intelligence, leadership, management.

\section{INTRODUCTION}

The world is characterised by political, social and economic environmental changes (Van Zyl, 2009). Internationalisation and globalisation for instance, have brought about world competition and require managers to interact with and manage people who are culturally diverse (Alam 2009; Alam et al., 2010; Penceliah, 2008). Africa is no exception to the global revolution that is sweeping across managerial and organisational thinking. Thus, Africa has seen a dramatic change in the way in which organisations and individuals within the business environment view culture, ethnicity, socioeconomics, gender and race (Penceliah, 2008; Sales, 2006). With an increasing number of culturally diverse African and foreign national employees entering the labour market, there has been a greater focus on culture than ever before

*Corresponding author. E-mail: vanzyles@ufs.ac.za. Fax: 0514019397.
(Sales, 2006).

Although Africans have been exposed to diverse cultures within a business organisational and occupational context, however, in today's complex and fastchanging world of multinational business where the workforce has become increasingly diverse in national and cultural origins and work assignments are more commonly performed by team members of varying nationalities, managing multinational teams is increasingly becoming a critical function (Van der Wal and Ramotsehoa, 2001).

The power of Africa and its long-term impact on global markets and economies are only beginning to surface and to be understood by the world, which will increase the pressure on leaders, as well as the complexity of leading businesses in the years to come. Africa has, for example, $60 \%$ of the world's uncultivated arable land. Furthermore, Africa's infrastructure projects represent $13 \%$ of the emerging market total and the need for development remains huge (Mckinsey's Global Institute, 2010). The increased global demand for Africa's 
resources, oil, gas and minerals will continue to grow, with increased returns for the continent. By 2040, Africa will be home to $25 \%$ of the planet's youth and will have the world's largest working age population. Lastly, the rate of return on foreign investment in Africa is higher than in any developing region (McKinsey's Global Institute, 2010).

Mkhize (2009) as well as Van der Wal and Ramotsehoa (2001) indicated that changing external realities could result in cultures, which were once effective, becoming ineffective. The external realities that face African organisations currently reinforce the necessity to identify the cultural gap, that is, the gap between actual and desired cultural norms, and addressing this to make organisations more effective. Unfortunately, modern and Westernised African organisations are conceptualised and structured in a Western mould (Van der Wal and Ramotsehoa, 2001). The cultures of organisations are dominated by the values of predominantly male top management structures, which ignore the fact that the largest proportion of the population is neither European nor American, but African (Van der Wal and Ramotsehoa, 2001). Many employees are unable to identify with these cultures and little congruence exists between organisational goals and those of the general workforce. Therefore, cross-cultural people skills are important because, managing people effectively is critical to organisational efficacy. According to House and Javidan (2001), the management of people is a result of the cultural forces in the countries and regions in which the leader functions. Leadership across cultural differences, whether international or organisational, requires specific interpersonal attitudes and skills, as well as technical and organisational knowledge (Manning, 2003). Zaidi et al. (2010) indicated the need for more effective leadership and decision making skills due to diversity in the working environment.

The aim of this qualitative research article therefore, is to discuss an appropriate and relevant way in which First World leaders can understand and approach their Third World workforce in Africa.

\section{DEFINING CONCEPTS}

Different concepts related to this research need to be understood and will be briefly discussed.

Culture refers to a group or community whose members share common experiences that shape the way in which they understand the world. It includes groups that a person is born into, such as, gender, race or origin, as well as groups that the individual joined or became part of (Penceliah, 2008). Cultural knowledge, on the other hand, refers to shared knowledge that accompanies the behaviour and practices of a particular group. In effect, cultural knowledge would be a deep understanding of the beliefs, customs and traditions of a particular group (Penceliah, 2008). According to Sackman (1992), cultural knowledge is necessary in organisational life and serves a crucial coordinating function as it is 'the body of knowledge that is drawn upon as a resource for explaining and making sense of new experiences'. Cultural knowledge is a fundamental building block in an organisation and, consequently, managing in a multicultural context would translate into building culturally appropriate relationships across various differences (Sackman, 1992). Cultural knowledge can give rise to cultural intelligence.

Cultural intelligence (CQ) provides managers with practical techniques for functioning effectively in any culture, as CQ is 'a person's capability for successful adaptation to new cultural settings, that is, for unfamiliar settings attributable to cultural context' (Earley and Ang, 2003). According to Earley and Ang (2003), cultural intelligence comprises a cognitive, emotional and behavioural component. The cognitive component refers to one's specific knowledge to perceive and understand a new culture based on various types of cultural cues. The motivational component refers to one's self-motivation and commitment to adapt and adjust to a new culture, and the behavioural component refers to acting according to one's commitment and new culture (Deng and Gibson, 2008).

In order to achieve cultural intelligence (CQ) in an organisational context, it is important to understand leadership and management issues and circumstances which are unique to the African context.

\section{LEADERSHIP AND MANAGEMENT IN AFRICA}

To improve cultural intelligence $(C Q)$ in the organisational context, leaders should try to achieve a better understanding of the changing African context, important crosscultural challenges and the African cultural value system.

\section{The changing African context}

Managers place a distinct focus on taking on the challenges prevalent in Africa's present-day business environment. As a consequence of the changes that accompany these challenges, a shift is taking place from cultural ethnocentrism based on self-praise, towards mutual respect between the races (Shonhiwa, 2006). This enables African countries to weave an entirely new economic tapestry, in which business is undertaken, creating an environment that differs markedly from that of the old Africa (Shonhiwa, 2006; Van Rensburg, 2007).

According to Van Rensburg (2007), the new environment has particular characteristics. Firstly, there is an 
emerging new class of management with an adaptable style of leadership that enables leaders to integrate the various cultures of those who answer to them. The changing economic landscape demands greater sensitivity and understanding of subtle cultural nuances in each particular country. Homebred management styles are developed that differ from those of multinational corporations and tend to be parochial, mostly owing to people's lack of exposure to different environments and challenges, while international players have the benefit of tapping into a wider source of knowledge (Van Rensburg, 2007).

The impact of culture and value systems, shape managerial response to similar business stimuli, for example, a bright, young person who questions the manager's instructions in order to understand them better might be seen as rude within an African context, but a European manager would welcome or even expect such input (Shonhiwa, 2006). Prevailing political and economic imperatives dictate the respective management competencies required in a particular situation. This means that a manager would be faced with the difficult task of trying to understand many new aspects of an unknown situation. Companies today, apply new critical success factors, which affect leadership and managerial effectiveness. The major key performance indicators in this regard, express a dire need for cross-cultural management and leadership skills which will enable managers to cope with the various demands in different countries (Van Rensburg, 2007; Mkhize, 2009).

Significant mega-trends ushered in a new value system, that influenced leadership style, can also be identified, that is, the arrival of the cash economy, which emerged through foreign traders (Van Zyl, 2009). The advent of the cash economy also created an entrepreneurial drive in those who are motivated to create wealth. Core African life emphasises humanity and relationships over material wealth and, thus, the focus on material values may clash with Africanism. Managers who pursue success too strongly may find themselves isolated from their staff or support group (Shonhiwa, 2006). Another change determinant is the evolution of the political system from traditional dynasties towards a more Western, democratic system, creating the problem of 'Senior Young People', who now preside over their elders by virtue of their political power. This situation currently pervades the entire business environment where 'Youngsters' have advanced up the corporate ladder and who are, in fact, the preferred high-flying managers (Van Rensburg, 2007).

\section{Cross-cultural challenges}

Mkhize (2009), Nussbaum et al. (2010), Shonhiwa (2006) and Van Rensburg (2007) indicated some cross-cultural challenges confronting African managers:

\section{Poor-rich individual}

The manager in the Afro-centric cross-cultural context is perceived by the rank and file to be materially and intellectually rich. This perception develops because poverty is rife on the African continent. Employees usually seem materially worse off than their managers, but very often, managers in the African context are not as well off as their employees may think. The erroneous perception that managers are rich can lead to complex personal problems for managers in the African context.

\section{Shifting ethical platforms}

The Cultural Revolution taking place in Africa leads to ethical boundaries being in a continual state of flux. What used to be taboo is now commonplace, as cultural goalposts are being shifted to suit new preferences. The conflict between old- and new-school managers further complicates the situation.

\section{Overriding political environments}

As political change occurs at a much slower pace than social and economic changes, managers continue to feel the weight of political restrictions. They are torn between patriotism and the demands of the new international business scenario.

\section{Cultural confines and conflicts}

In some scenarios, managers are unable to support a specific change or product because it will clash with tradition, and they feel they cannot risk being the first to step out of line.

\section{Skills and productivity gaps}

Although advances in technology surge onwards, the process of upgrading skills is lagging behind, creating a widening productivity gap. Most African governments prevent the inflow of foreigners in order to retain employment for locals. However, managers fail to meet targets due to a lack of skills in the available workforce.

\section{Society's crisis of expectations}

In an African context, one is not sure whether to openly 
celebrate one's success or if this behaviour will be construed as arrogant and boastful. The majority of African society is still operating in a communalism mode, expecting all citizens to be either equally poor or equally wealthy. Those who are first to achieve higher status, such as a management position, are targets of the African PHD ('pull-him-or-her-down') syndrome. This places the cross-cultural manager in a frustrating pushpull position.

From the aforementioned, it is evident that the African value system must be well understood before any effective leadership system can be implemented. Therefore, the focus of further discussion will be on the African cultural value system.

\section{The African cultural value system}

It is clear that the effective cross-cultural manager should have an in-depth understanding of the African cultural value system which determines the behaviour of subordinates. This value system can be summarised as (Khoza, 2005; Mbigi, 2005; Shonhiwa, 2006; Van Rensburg, 2007):

i) The African prefers spiritual collectivism to individualism. Spiritual guidance is expected and respected;

ii) There is an inclination towards consensus in problemsolving, rather than dissension;

iii) Humility and helpfulness are expected, instead of wanton criticism. The spirit of ubuntu (the concept of fellowship, loosely translated as you are who you are through other people') is greatly valued and each person is very much conscious of this philosophy;

iv) There is an inherent trust and belief in the fairness of those in leadership, hence a lack of criticism;

v) African moral standards are based on ancestral precedents and, thus, history plays a prominent role in guiding future conduct;

vi) Society is a structure in which an inclusive system of hierarchy plays a role. This inspires orderliness and acceptance of authority;

vii) Perpetual optimism and a belief in superior forces underlie the African sense of being and attitude towards life. This explains the ease with which fanatic allegiance is instilled into the minds of young people who become guerrilla fighters; and

viii) There is a tacit expectation that those who are in a supervisory position will display sound leadership and not let their subordinates down. Subordinates expect their leaders to display a heightened sense of ethics, fairness, transparency and accountability. Unfortunately, many leaders today fail to uphold these values.

\section{A CULTURAL INTELLIGENCE IMPLEMENTATION MODEL BY WHICH FIRST WORLD LEADERS CAN ATTEMPT TO UNDERSTAND AND APPROACH THIRD WORLD SUBORDINATES}

In order to improve the cultural intelligence (CQ) amongst leaders (by means of understanding and managing people from diverse cultural groups), the following adapted model of Van de Wal and Ramotsehoa (2001) can be considered (Figure 1).

From Figure 1, it is evident that there are four cornerstones which contribute to organisational success and effectiveness. Each of these cornerstones will now be discussed.

\section{Cornerstone 1: Commitment from top management}

Arsenijevic et al. (2009) as well as Wang and AbdulRahman (2010) are of the opinion that culture of every organisation is to a great extent, defined by leadership. Lundin and Nelson (2010) are of the opinion that top management should come to the conclusion or understanding that the business and social culture is business; this must be a believe set, not only words or lip service.

In order to focus on the business and social culture as well as to improve cultural intelligence amongst leaders and employees, top management should be committed to improving their own cultural intelligence, as well as that of subordinates.

Dalglish and Therin (2003) are of the opinion that, it is the primary responsibility of top management to instruct, motivate and inspire their employees with regard to openness towards other cultural groups. Lundin and Nelson (2010) indicated that top management should live the new values and purposely influence the leaders below the executive team. Furthermore, top management should set a company policy with regard to cultural openness and the improvement of cultural intelligence which should be communicated clearly to all employees. Employees should be told and retold in unmistakable terms that the company is firmly committed to cultural openness and improvement of cultural intelligence in all its activities (Dalglish and Therin, 2003; Nussbaum et al., 2010).

\section{Cornerstone 2: Create a shared value organisational culture}

Arsenijevic et al. (2009) and Dorasamy (2010) acknowledged the importance and crucial role of the culture of an organisation in the productivity and learning at all levels. Zaidi et al. (2010) explained that good performance and effective decision making are achieved 


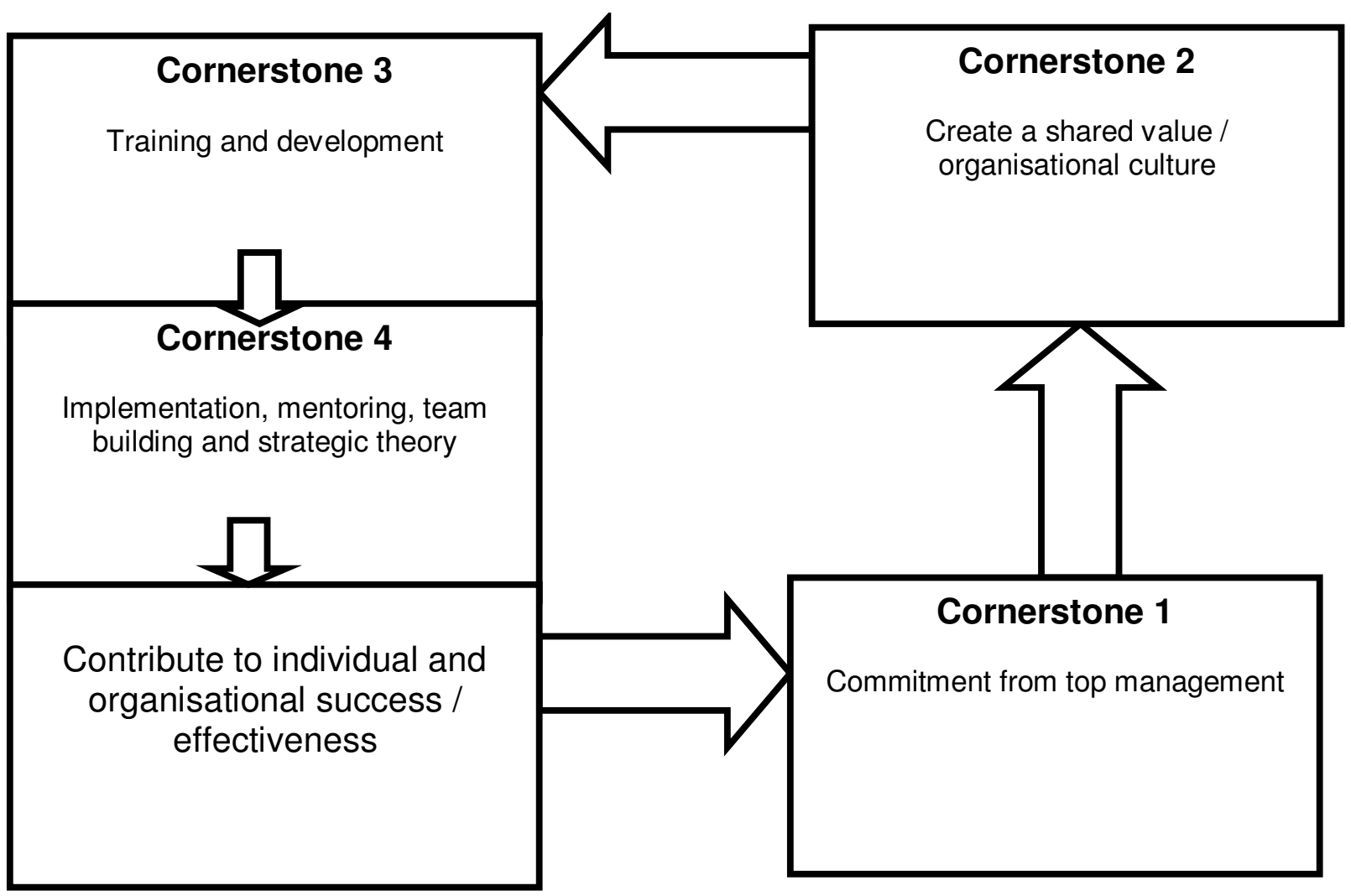

Figure 1. A cultural intelligence implementation model (adapted model from Van de Wal and Ramotsehoa, 2001).

through teamwork and a shared value system within the organisation.

According to Penceliah (2008), the focus on improving the cultural quotient (CQ) of employees can aid in the understanding and management within a diverse cultural environment. By being culturally intelligent, one can develop skills and an understanding regarding culture, learning more about it from one's own interactions with adherents of the specific culture, and gradually reshaping one's thinking to be more sympathetic towards that culture. Sales (2006) argues that having the necessary knowledge and understanding of cultures will no doubt empower managers to instil trust and confidence in their employees and to appreciate the values and norms of their staff.

Van der Wal and Ramotsehoa (2001) indicate that the cultural quotient of employees can be developed by means of implementing ubuntu within the organisational culture. Ubuntu, embraces a set of social behaviours, such as sharing, seeking consensus and interdependent helpfulness which, if recognised, valued and incorporated into the culture of organisations, could yield considerable positive outcomes on business results. Karsten and IIla (2005) as well as Lundin and Nelson (2010) define ubuntu as a pervasive spirit of caring and community, harmony and hospitality, respect and responsiveness that groups and individuals display towards one another. They are also of the opinion that ubuntu represents a specific African worldview, which can further be translated into the 'African dream in management'. It is the label that covers the way in which members interact and share experiences. Ubuntu, therefore, strives to reach beyond a purely managerial approach and strengthens an attitude of listening to one another and to open conversations. Karsten and IIla (2005) indicate that storytelling, inclusive decision-making and participatory team meetings are key features of ubuntu. The setting of an organisational culture is the function of the top management of that specific organisation, and top management should therefore, be responsible for implementing ubuntu into the organisation's culture.

\section{Cornerstone 3: Training and development}

Zaidi et al. (2010) explained that differences in the organisation could lead to conflicts. Conflicts however can be resolved through improved human resource policies, 
effective communication, participative decision making and a constant training schedule within the organisation (Zaidi et al., 2010).

According to Van der Wal and Ramotsehoa (2001), training that provides an understanding of the values, beliefs, customs and preferences of the other group will enhance cultural diversity. Developmental sessions by means of practical workshops can be held where people of different cultural groups discuss areas of similarities and differences with regard to cultural values and behaviour. Communication sessions, focusing on 'where are we now and where do we want to go' should be implemented in the organisation (Nussbaum et al., 2010).

Every employee should be given the opportunity and responsibility to improve their cultural intelligence. To achieve this, the following steps can be taken (Karsten and IIla, 2005; Lundin and Nelson, 2010; Nussbaum et al., 2010):

i) Obtain knowledge about the cultures of different employees. Language courses, programmes focusing on breaking cultural barriers or stereotypes, and the valuing of cultural differences, should be focused on;

ii) Develop special events or schemes to expose employees (and managers) to people from different cultural groups; and

iii) Provide effective training in order to improve skills in listening, interpersonal communication, conflict resolution and negotiations, and explore ways to alter current assumptions and paradigms. Workplace teams should utilise these skills, as well as reinforce diversity efforts.

\section{Cornerstone 4: Implementation: Mentoring, teambuilding and strategic thinking}

Van der Wal and Ramotsehoa (2001) assert that employees should be empowered by means of relevant mentoring in the organisation. A mentoring system in the organisation can develop a sense of competence and professional identity which, in turn, will help employees to mature personally. Agumba and Fester (2010) explained that mentoring refers to an interactive and dyadic relationship with a senior and experienced employee. By having an interactive relationship with an experienced person, complex issues with regard to new culture/values can be sorted out (Agumba and Fester, 2010). Agumba and Fester (2010) highlighted the following characteristics mentors should have; be approachable, have selfconfidence, show desire to be a mentor, provide honest feedback, be self knowledgeable and be dedicated to mentoring.

Teambuilding can be used to build a culture of intercultural understanding. In this way, enhanced communication channels between supervisor and subordinates can be established. This can lead to an improvement in work co-operation and can provide a useful basis for the introduction of permanent problem solving groups at work (Nussbaum et al., 2010; Van der Wal and Ramotsehoa, 2001).

Visions, missions and objectives should be modified according to the new culture in the organisation. The involvement and participation of all employees in the planning, wording and setting of the new vision, mission and objectives will help to commit everyone to implementing the new value system (Nussbaum et al., 2010). Alam et al. (2010) are of the opinion that if employees are well informed with strategic objectives and values, trained and involved with the implementation of that, work quality and accountability will be the result.

Weibo et al. (2010) indicated that new values will only become shared values in organisational context if it is being lived by all employees in the organisation. Living it means the constant evaluation of how successful aligning between business and social culture are taking place. This may imply that subtle changes may be required on a constant basis that will have to be filtered through to the organisation (Weibo, et al., 2010).

Van der Wal and Ramotsehoa (2001) indicate that the afore-mentioned cornerstones can contribute to individual/organisational effectiveness which, in turn, can have a positive influence towards improving the four cornerstones.

\section{SERVANT LEADERSHIP AS A TOOL TO IMPLEMENT THE CULTURAL INTELLIGENCE IMPLEMENTATION MODEL}

According to West et al. (2008), a leadership style that has emerged with great intensity over the past few years is that of servant leadership. Greenleaf introduced servant leadership by stating that leaders are to be servants first, for it is the proven record of service that provides the basis on which the led, choose those whom they will follow (Irving, 2008; Joseph and Winston, 2005).

West et al. (2008) claim that servant leadership, in many ways, provides answers to some of the cultural and ethical dilemmas faced by people in businesses and other organisations. Larry Spears, president and CEO of the Greenleaf Center for Servant Leadership, identifies two primary reasons for the rise in importance of servant leadership, that is, people in today's workplaces are generally dissatisfied with the level of caring and encouraging behaviours they experience at work and that servant leadership provides a different approach which answers contemporary expectations better than do traditional leadership models. He also suggests that businesses and other organisations which practice servant leadership increasingly find themselves at the top 
of their industries, primarily due to their having the ability to better meet customer, client and community expectations (Joseph and Winston, 2005).

Mumley (2007) discusses the fact that servant leadership factors, such as love, humility, altruism, incurporation of the followers' vision, trust, empowerment and service, correspond well with the ubuntu ideal in African companies.

$\mathrm{He}$ further indicates that the connection of servant leadership with the indigenous values of ubuntu represents a significant breakthrough in the potential of implementing servant leadership theory throughout African companies. Creff (2004) is of the opinion that servant leadership provides a bridge by which ubuntu can be applied within African companies. He also states that a concerted, wise application of servant leadership should be practiced through training and development actions within organisational context.

West et al. (2008) explored cultural constructs of transformational and servant leadership theories and describe differences that include; (a) transformational leadership that accounts for intellectual stimulation where servant leadership does not; and (b) servant leadership that stresses employee's well-being where transformational leadership does not.

Although some researchers (Smith et al., 2004) postulate that it will be difficult to implement servant leadership in a very dynamic, high-demanding work environment, the following research indicates the successful implementation of servant leaderships in public and private companies:

i) Servant leadership with organisational outcomes (West et al., 2008).

ii) Servant leadership with organisational culture (Smith et al., 2004).

iii) Servant leadership with team effectiveness (Irving, 2008).

Finally, West et al. (2008) indicate that characteristics of the servant leader, such as building trust, caring, developing others, sharing leadership, listening before speaking, building community and providing leadership, are probably the best way to undertake cultural changes within the modern company today.

\section{CONCLUSIONS}

According to Karsten and Illa (2005), 'It is not our differences that divide us, it's our judgments about each other that do'. Cultural differences are rarely the source of interpersonal or inter-group conflict. The most common source is what can be called 'mindsets', such as filters, through which people view the world, the self and others
(Karsten and IIla, 2005). Influenced by their mindsets, some people appreciate and work effectively with individual and cultural differences, while others are awkward, threatened or uncomfortable (Mumley, 2007).

To meet the challenge of a diverse workforce, managers in the African context need to develop a greater appreciation of understanding and managing Third World subordinates with different value systems. In the African context, the need exist to emphasise the affirming of different values which will create a corporate environment where individuals will reach their potential to the benefit of their organisation. By improving cultural knowledge (and implementing the cultural intelligence implementation model), the ability to better meet employees, customers, clients and communities' expectations, improve (Mumley, 2007). This could lead to a more effective and sufficient work environment and to improved individual/organisational performance. Servant leadership can be a critical tool to implement cultural knowledge and the cultural intelligence implementation model within the organisational context.

Leaders/managers in the African context have the responsibility to not only focus on improved productivity amongst employees, but also to set an example of commitment to the cultural values of others and how these can be implemented in the organisational context (Van der Wal and Ramotsehoa, 2001). Perhaps, this spirit was best captured by Lao-Tzu, the $6^{\text {th }}$-century Chinese philosopher (Van Zyl, 2009), who wrote: 'A leader is best when living to potential and understands others fully in order to help them to reach their potential to the benefit of everyone involved.'

\section{REFERENCES}

Agumba JN, Fester FC (2010). Participation in formal mentoring programme in South Africa construction industry: a perspective of new knowledge workers. Afr. J. Bus. Manage., 4(10): 1954-1963.

Alam GM (2009). Can governance and regulatory control ensure private higher education as business or public goods in Bangladesh? Afr. J. Bus. Manage., 3(12): 890-906.

Alam GM, Ismael LI, Mishra PK (2010). Do developing countries need Education laws to manage its system or are ethics and a marketdriven approach sufficient? Afr. J. Bus. Manage., 4(15): 3406-3416.

Arsenijevic J, Tot V, Nesic LG, Andevesk M, Arsenijevic D (2009). Correlation of experimenting culture and process of knowledge management in the University environment. Afr. J. Bus. Manage., 3(10): 521-532.

Creff K (2004). Exploring ubuntu and the African Renaissance. First Global Servant Leadership Research Roundtable. Servant leadership and organisational outcomes, Rotterdam.

Dalglish C, Therin F (2003). Leadership perspectives. Brisbane: Queensland Press.

Deng L, Gibson P (2008). A qualitative evaluation on the role of cultural intelligence in cross-cultural leadership effectiveness. Int. J. Leadersh. Stud., 2: 181-197.

Dorasamy $N$ (2010). The impact of global crisis on ethical leadership: a case study of the South African public sector. Afr. J. Bus. Manage., 4(10): 2087-2096.

Earley PC, Ang S (2003). Cultural intelligence: An analysis of individual 
interactions across cultures. Palo Alto: Stanford University Press.

House R, Javidan P (2001). Project Globe: an introduction. Appl. Psychol., 50: 489-505.

Irving JA (2008). Utilising the organizational leadership assessment as a strategic tool for increasing the effectiveness of teams within the organization. J. Manag. Mark. Res., 1: 111-124.

Joseph EE, Winston BE (2005). A correlation of servant leadership trust and organizational trust. Leadersh. Organ. Dev., J. 26(1): 6-22.

Karsten L, Illa H (2005). Ubuntu as a key African management concept: Contextual background and practical insights for knowledge application. J. Manag. Psychol., 20: 607-620.

Khoza RJ (2005). Let Africa lead. Johannesburg: Vezebuntu Publishing, Lundin S, Nelson B (2010). Ubuntu. New York: Broadway Press.

Manning TT (2003). Leadership across cultures: Attachment style influences. J. Leadersh. Organ. Stud., 9(3): 20-30.

Mbigi L. (2005). The spirit of African leadership. Randburg: Knowres Publishing.

McKinsey Global Institute (2010). Lions on the move: The progress and potential of African Economies. London: Mckinsey and Company.

Mkhize VVO (2009). Umsamo: the new African business literacy. Johannesburg: Knowres Publishing.

Mumley WE (2007). Cross-cultural understanding of power in servant leadership theory. Available: www.globalmissiology.org.

Nassbaum B, Palsule S, Mkhize V. (2010). Personal growth African style. Johannesburg: Penguin Books.

Penceliah, Y (2008). Managing across cultures for organisational success. J. Public Adm., 43(3): 330-341.
Sackman S (1992). Culture and subcultures: An analysis of organizational knowledge. Adm. Sci. Q., 37(1): 140-161.

Sales C (2006). Organisational culture in multinational organisations. J. Contemp. Manag., 3: 60-76.

Shonhiwa S (2006). The effective cross-cultural manager (a guide for business leaders in Africa). Paarl: Struik Publishers.

Smith BN, Montagno RV, Kuzmenko TN (2004). Transformational and servant leadership. Int. J. Manag., 13: 34-40.

Van der Wal R, Ramotsehoa M (2001). A cultural diversity model for corporate South Africa. Manag. Today. 2: 14-22.

Van Rensburg G (2007). The leadership challenge in Africa. Pretoria: Van Schaik.

Van Zyl ES (2009). Leadership in the African context. Cape Town: Juta.

Wang C, Abdul-Rahman (2010). Decoding organisational culture: A study of Malaysian construction firms. Afr. J. Bus. Manage., 4(10): 1985-1989.

Weibo Z, Kaur S, Jun W (2010). New development of organisational commitment: A critical review (1960-2009). Afr. J. Bus. Manage., 4(1): $12-20$

West GRB, Bocarnea MC, Dioscoro A (2008). Leadership of organizational networks. Int. J. Serv. Leadersh., 8(6): 19-31

Zaidi SMA, Saif MI, Zaheer A (2010). The effect of workgroup heterogeneity on decision making. Empir. Investig., 4910): 21322139. 